\title{
Colonialist theatre education in Botswana
}

\author{
Chandel Gambles
}

\begin{abstract}
This manuscript was prepared under the supervision of President Alastair Summerlee and Professor Jacqueline Murray,
\end{abstract} Department of History, College of Arts.

\begin{abstract}
There is a distinct lack of theatre in Botswana due to its political and social history. The colonialists of the past and the artistic Theatre for Development educators have forced outside theatrical ideals on Botswana productions. When the majority of the country was illiterate, this was the most effective tool for establishing propaganda and communication. However, since the economic welfare and educational standards of Botswana have improved, educators should not be as dependant on theatre as a tool. Theatre for Development still dominates current productions and has caused a distinct hindrance of creative discovery within the country. Until the topics and creative stylizations of the indigenous people are accepted and promoted, the nation cannot hope to reflect their distinct culture through theatre.
\end{abstract}

"For any thing so o'erdone is from the purpose of the playing, whose end, both at the first and now, was and is, to hold as 'twere the mirror up to nature; to show virtue her feature, scorn her own image, and the very age and body of the time his form and pressure." ${ }^{21}$ - Hamlet

$\mathrm{T}$ heatre has been found throughout history, representing each culture and its evolution through a combination of visual and audio experiences. Louis Harrap explains that one of the major functions of the arts is that it "contributes to the shaping of consciousness and has played a part in moving people to social action". ${ }^{18}$ Theatre acts as the voice of the people and affects society by promoting reflection and change. As Shakespeare's Hamlet explained, the function of the performance arts is to allow audiences to reflect upon culture, intentions, and the world at large.

When there is a distinct absence of theatre within a culture, one must consider the cause. In a country as expressive in song and dance as Botswana, it is strange to note that theatre is distinctly underrepresented within the culture. When it is present, theatre is used primarily for the purpose of education. As educational programs adopted performance as a medium of communication, theatre for selfexpression became progressively absent. This paper is based on personal fieldwork in Botswana and the insight gathered by engaging in San community celebrations. By analyzing the history of colonialist theatre in Botswana, the prominence of Theatre for Development productions, and community presentations, it is evident that educational theatre has remained the main intention of theatre in Botswana, which has led to the decline of theatre performances within the country.

\section{DEFINING THEATRE}

For the purpose of this paper, it is important to define the term "theatre" in this context. The term is associated with specific performance locations, but it is not actually restrained by the confines of space. Theatre productions can be presented in any environment and can use a variety of different mediums and technological tools.

Across the globe, theatre is appropriately defined as performance based on a comprehensible storyline that can transcend language barriers. Theatre allows for the presentation of ideas through visual and audio cues. ${ }^{6}$ Although theatre often utilizes both song and dance movements during its presentation, these components do not constitute theatre when they are considered to be separate entities. The combination of theatrical cues brings a higher dynamics and imagery to the basic structures, thereby allowing the storyline to be communicated. "Every culture has its own traditions of performance and theatre, its own forms and modes of artistic expression. Equally, each culture has its own framework". ${ }^{20}$ Even though the methods for transmitting the message oppose the techniques that are generally found in North American theatres, the combination of performance tools allow foreign viewers to analyze and comprehend a portion of the ideas.

Although theatre exists in Botswana, it is not widely recognized or defined by a specific term. "Most African cultures and languages, in fact, seem not to have specific words for theatre or drama". ${ }^{20}$ This explains why, when asking about Botswana's theatre history, the question was met with uncomprehending responses. Translating "English to Setswana" through the online dictionary Dicts.info, the site claims that the English word for music is translated as 'kopelo', dance is 'mmino', and drama is 'tshameko'.' However, no word appears to describe the combination of 
these artistic activities and the communication of concepts through theatrical performances. 'Theatre' does not exist in the Setswana vocabulary. One might wonder if the absence of this language tool is associated with the distinctly marginal presence of theatrical performances found in Botswana. Theorist Jacques Derrida explained that both writing and the spoken language are essential to human understanding. For Derrida, "there is nothing beyond the text". ${ }^{10}$ An object can exist without a name, but without proper recognition it cannot be easily identified or utilized.

It would be incorrect to say that Botswana has no theatre, because that would discount much of the educational theatrical programs and skits that have been produced. Theatre represents a small percentage of overall performances in Botswana. The Maitisong Festival is a celebration of the performing arts that features "theatre, traditional music and dance, marimba bands, choirs and a range of more western-influenced styles of dance and music". 8 Many other music festivals also exist and the Botswana Musicians Union holds an awards ceremony for the country's artists each year. However, there is very little mention or evidence of theatre performances at a local level. To understand the current position and use of theatre, one must look at its history.

\section{COLONIALIST IMPACT ON THEATRE}

The current absence of theatre from Botswana's cultural landscape can be partially attributed to the effects and influence of colonialism. The conquest and oppression of African countries by the West inevitably altered cultures, lifestyles, and other aspects of life, including communication. Colonial governments "encouraged low literacy levels among local indigenous populations by fostering apathy towards national development and culture and lower modes of consciousness". 5 The colonialists controlled the local populations by discouraging and restraining their individual rights, powers of communication, and sense of culture.

Ritual played an important role in traditional African society. Although the international origins of theatre are still debated, it is widely believed that theatrical performance developed through sacred rites. "The aesthetic qualities embedded in the ceremonies is not fully recognised, in spite of the acknowledgement that most of the action of these ceremonies is performed through song, dance, mime, and even dialogue". ${ }^{17}$ Certainly, theatre performances are not the same as rituals, since one is believed to be true and the other is performed as a representation of life. To claim that rituals are the same as theatre would devalue and insult those sacred acts.

Despite their different purposes, the two performance activities share similar elements of communication. Theatrical elements were often utilized to acknowledge significant events within the communities, such as births, deaths, and harvests. There is also evidence of drama through the impersonation of spiritual figures. "The evidence of rock paintings of masked figures found in Tassilli, Algeria, South Africa, and Libya in the 1950s attest to man's knowledge of impersonation as far back as 3500 to $1500 \mathrm{BC}$ ". Since ritual could be considered the first exploration of theatrical techniques, events that affected ritual presentations also affected the future of theatre.

The arrival of the Europeans led to a wave of theatricality. Not only did these European colonialist groups bring their own religions and values into Africa, but they also brought their own theatrical performance styles. "Rituals were deemed hedonistic and consequently outlawed, leaving European cultural forms as the only legitimate alternative sources of religion and entertainment". $5 y$ suppressing the rituals of the indigenous people, the colonialists gained power and influence through suppression. "Their intention was not only to entertain the European community in the colonies but also to inculcate European values and attitudes among the colonised as part of the cultural domination crucial to the colonisation process". ${ }^{18}$ Europeans were then able to spread their ideology and 'educate' the African people through the use of performance art propaganda.

Missionaries, in particular, preferred to utilize European dramatic forms to promote their religious agendas. "The arrival of Christian missionary groups in the nineteenth century saw the development of the folk operas, which were based on the entertainment in the churches. Traveling groups of actors performed these operas on tours throughout Africa". 23 Christian morality dramas enacted the Biblical stories. "Open propaganda was therefore the main objective behind efforts to create drama among Africans". ${ }^{23}$ By utilizing the same performers and performance content, the missionaries were able to spread their religious doctrine throughout Africa, 'educating' the indigenous people as they saw fit.

The use of visual aids ensured the promotion of the Christian message, while avoiding the problem of translating the Bible for the indigenous people. Theatrical performance allowed for communication while restraining the local populations through the perpetuation of illiteracy. Education through theatre was encouraged, but it also allowed the continuation of repression that extended the period of underdevelopment for countries under colonialist rule.

\section{INITIATION OF THEATRE FOR DEVELOPMENT}

Aspects of Theatre for Development began emerging in education programs across the developing world throughout the 1940s and 1950s. New educational techniques were required to inform the public of political, social and health concerns, due to the low literacy rates in those countries at the time. Didactic mobile theatre was eventually introduced in the 1950 s as experiments by colonial governments. "The tours were a form of 'mass education' to complement and 
reinforce a process of community development and extension work at the local level". ${ }^{14}$ Like the colonialist leaders of history, these new post-colonial governments overcame the barriers of illiteracy by utilizing theatre presentations.

The 1993 literacy survey ultimately provided proof of the nation's illiteracy. In a report to the UNESCO Institute for Education in 2005, Dr. Hanemann explained, "M. Commeyras and B. Chilisa, who made a comprehensive critique of the survey, reached a negative conclusion about the usefulness of the statistical profile produced by the survey. The result that $69 \%$ of the population is literate sounds impressive until one sees the low level of literacy that was assessed". "The questions were too simple to prove literary comprehension. Furthermore, "respondents were categorised as literate if they scored $50 \%$ or more in the test". ${ }^{11}$ By inference, it can be assumed that literacy rates were even lower when the country first became independent in 1966 .

Against this educational background, one can comprehend why theatre is considered to be preferable to the other communication alternatives. Theatre is a viable tool to provide positive opportunities for problem solving and to encourage involvement in the application of social and political solutions. It provides an artistic forum where groups can "concretize and forces the analysis, to test out alternative strategies and bring out fresh contradictions and constraints" when problem solving. ${ }^{14}$ By using theatre, educators can avoid the communication barriers that illiteracy creates.

There are many possible benefits that can arise from using theatre as the communication medium to promote community development. If the viewers do not have a strong understanding of the official national language, the native speech and dialects of each locality can be adopted for each specific presentation. Second, a visually appealing and entertaining medium also has a stronger chance of maintaining viewer interest. Last, the use of collective expression and communal performances allows communities to address the issues as a cohesive unit. ${ }^{15}$ Consequently, people can engage in peer learning strategies and horizontal communication to develop their understanding, rather than listening to top-down monologues from the government and program initiators. These notions were encouraged within the agenda associated with 'Theatre for Development'.

The term 'Theatre for Development' (TfD) was coined in Botswana in 1973. The term exhibits the distinct purpose of using theatre as the vehicle for raising consciousness. Literacy educator Ross Kidd led the campaign. The first experiment to use popular theatre for non-formal education in Botswana was a project called, Laedza Batanani, which loosely translates to "community awakening". "The program was developed under the auspices of the University of Botswana's adult literacy program". It was then funded by the Canadian University Services Organization and took place in the Bokalala District from 1974 to 1977. The project's basic goal was "to find a way of motivating people to participate in development, and of mobilizing the community around important local issues". ${ }^{15}$ Its rallying slogan and theme song were, "The sun is already up. It's time to wake up and come together for a common effort". ${ }^{15}$ The slogan claims that the problem is with the indifference of the communities. The creators used theatrical education to inspire individuals to get involved in the government development efforts, rather than to question why there was a lack of participation in the first place.

The theatrical education was successful at provoking participation, but did not carry-over into the daily lives of the viewers. Sensitive topics were related within the safe environment of the workshop, which allowed marginal community groups to be heard. Female participants praised the project, saying, "Laedza Batanani is a good way of getting people to talk about problems - easier than wives on their own trying to argue with their husbands. The drama helps to show men what women don't like". ${ }^{15}$ These workshops allowed discussions to occur, but there is no evidence that they influenced or changed everyday lives. "Such developments occurred solely in the forum of the performance and were not carried over to the villager's lives". The focus of the activity was not long-term, because "The analysis is limited to the village rather than the entire social formation to which it is part". ${ }^{15}$ Long-term change could not occur, due to a lack of resources after the program was completed. Rather than analyzing the system that supported the current activities and ideology, the project focused on symptoms alone.

Another problem with Laedza Batanani was the fact that the community members were not involved in the preparation. Initially, organizers had identified popular participation as a major objective. Unfortunately, they only "encouraged involvement from community leaders who held elevated positions of power in the community, diminishing the involvement of ordinary villagers". 5 Rather than interacting with various groups in each community, the educators conversed with the 'upper levels' of village society. In the final report, Kidd admitted that "A realignment with the original goals would require a shift towards genuine popular participation by moving away from an undifferentiated community-wide approach to a more strategic approach directed to the most oppressed sectors of the rural community". ${ }^{14}$ The asymmetrical involvement created a skewed representation of the issues facing the average individual.

Despite these problems, the Theatre for Development approach was used again. Popular theatre was recognized as "an important tool for raising sensitive issues which might otherwise never be dealt with, provoking people to talk about them, and providing a forum to discuss them". ${ }^{15}$ It was promoted in Tanzania, Malawi, Namibia, Lesotho, South Africa, and Ghana. ${ }^{14}$ Each country used theatre for educational purposes, with varying levels of success. 
Theatre cannot independently cause change. It is simply a tool, a catalyst to provoke thought and change through education and debate. Its function is social transformation, and for that reason it is relevant to humanity. If inspired, a performance can promote viewers towards practical action, but there must be support systems readily available to assist viewers in their efforts. If the appropriate networks are not available, the stimulation elicited by the performance will dissipate. In order to achieve long-term success, an entire network of follow-up conversations, community organizations, and government programs need to be in place before the performance occurs.

\section{Local COMmunity Theatre}

As Shakespeare's Hamlet explained, theatre engages the audience in the contemplation of life by providing an entertaining medium where audiences can see a reflection of their own interrelations. Thus, the audience is integral to every production. Without a viewer, theatre has no purpose. ${ }^{6}$ Understandably, people do not engage with performances that do not interest them. The show must be either insightful or entertaining. Theatre cannot successfully be used to preach to an audience or enforce the agenda of the actors and sponsors unless the audience responds to the message.

Going into the San communities of Botswana today, observers can see a variety of dances and songs that represent their culture. During a recent trip to Botswana I was given the opportunity to experience San culture, which included witnessing re-enactments of various rituals and ceremonies regarding healing, celebration, and coming of age. Less obvious however, was the use of theatrical skits, although these too are used to portray stories on special occasions. The theatrical presentation that I witnessed showed how theatre education is utilized during community performance.

The San performers created a theatre skit to allow their visitors to recognize the importance of unity and the roles of individuals and families within their village. Two performers presented the characters of a husband and wife. In that community, it is the man's duty to return home from the hunt with a prize, otherwise he has shamed his wife. During the skit, the wife is upset because her husband failed to provide. She proceeds to tell him that she has no water for him, and dumps it on the ground. The message that is established is that both individuals must equally participate in the maintenance of family needs. If one person fails to complete their obligation, then that person is not entitled to receive the benefits that the other provides. The husband leaves again, returns to the home with his prize, and is greeted with the gift of water. The other actors then perform celebratory songs and dances to show how equality and unity are established to maintain the community.

This presentation was highly successful in relaying its message, because it reached the audience through many performance techniques and tools. The audience members from the village listened to the dialogue in their mother tongue and laughed at the jokes and the demands that the actors made of each other. They were watching members of their village present topics that interested and defined their community. They also saw their own dances and heard the songs that they enjoyed together during celebrations. The performance did not cater to the foreign audience members. However, we were able to follow the storyline by watching both the interaction between the performers and the responses of the San audience. The use of theatre helped convey the social expectations of that community. The visual indicators and audience responses allowed the premise to transcend communication barriers.

By invoking the interests of the community members, the skit addressed the interests of the majority of the audience. The production utilized familiar songs and dances, included humorous dialogue and interaction to maintain its entertainment quality, and it encouraged community involvement in the practice and performance process. The theatrical presentation spoke to the audience, rather than at it. By allowing the community to explore the problems they face, both indigenous and foreign, viewers have a better opportunity to analyze the portrayal of the San culture.

\section{Creating a Theatre INDUSTRY}

In the 1980s, community performances were described as a common occurrence in Botswana. After the day's work was complete, individuals would invite their friends to see them perform in a common gathering place. ${ }^{16}$ There was no economic or social development agenda that led the showings. Performance was simply used as an opportunity to unite the community members by sharing their culture.

Two factors came into play at the time which altered the future of theatre. The first change was the purpose of performance. In an interview, a Motswana man reflected that, "They wanted to turn it into a business. It wasn't a time to gather anymore. They wanted it to become an industry that people did for money". ${ }^{16}$ This is different from the original mandate of most African productions. Theatre professor Dr. Okagbue of the University of London explains:

Performance activities in African cultures are not done ostensibly for any immediate material reward for the participants. They may however be done with a hope for possible future benefits for those involved in the doing or for those for whom they have been organized, and for the good of the community as a whole. And finally, these activities are marked out by the fact that they are sometimes done just for the joy and fun which they bring to all who take part. ${ }^{20}$

The theatre found in Botswana continues to focus on social and cultural difficulties even when it does not have an explicitly Theatre for Development educational agenda. Ethically speaking, if the performers continued to present the 
accepted political content, they would be acquiring financial gain at the expense of community values. Consequentially, viewers would begin to question the performer's purpose and the intentions behind the art.

Even if the Batswana audiences were willing to promote such a commercial industry, that does not take into account the restrictions of the country's economic situation. Since independence, Botswana has experienced strong economic growth through the development of the diamond industry. It has come to be considered a middle income country, with a real GDP of \$27-billion dollars in 2008 . $^{3}$ However, although the country's financial situation has improved and is financially superior to many of its neighbours, as of January $2003,30.3 \%$ of the population in Botswana lives below the international poverty line of US $\$ 1.25$ per day. ${ }^{3}$ One can therefore conclude that the average citizen does not have the luxury of attending live entertainment regularly. Theatre is not a necessity, so it will not thrive if the average person is concerned about acquiring basic living necessities.

\section{ThEATRICAL AIDS EDUCATION}

The second defining theatre trend for Botswana was initiated with the promotional awareness of AIDS during the mid 1980s. In 2001, UNAIDS statistics showed that $73 \%$ of the world's deaths that were caused by HIV/AIDS occurred in Africa. Southern Africa experienced the highest rates, with Botswana leading at an adult prevalence rate of $38.8 \%{ }^{4}$ The high infection rates in Africa encouraged the creation of a theatrical movement that was developed to raise awareness and discourage the accidental transmission of HIV/AIDS. "Plan International, ENDA Tiers Monde, and other INGOs use Theatre for Development to warn people against the spread of AIDS. So do a host of other projects supported by the bilateral aid winds of the U.S., Canada, and the European Union". 4 There are numerous examples of various performance styles that were utilized for the abundant inflow of AIDS communication campaigns in Botswana and the rest of Africa.

With a sudden and continuous upswing in plays about AIDS awareness during the initial outbreak, the topic overshadowed all other theatre subjects. "Every time I go they do a show about AIDS, and there's really nothing we can do about getting it. Why would I see a show I've seen before? That's the only theatre there is". ${ }^{16}$ The performances were consistently didactic in their effort to inform the masses about AIDS symptoms and prevention techniques. With time, the presenters began to lecture audiences on an overrepresented subject, causing educators to run the risk of insulting, ostracizing, and annoying their viewers. The only reason to repeat the discussion of old topics in theatre is to provide an audience with the opportunity to acquire new and/or unique information. This is a particularly important notion for educational performances, because they are in the business of communicating new information.

Since its discovery in 1982, the spread of AIDS has become more controlled in Botswana. UNICEF statistics show that the prevalence of HIV/AIDS in the adult population, as of 2007 , is estimated at $23.9 \%$. This constitutes a $14.9 \%$ drop in adult infection rates, which is impressive for a six-year period. ${ }^{3}$ The UNICEF website claimed that it "is working closely with the government to expand testing, treatment and prevention efforts, with a special focus on supporting affected children". "The government and associated health programs have taken great strides to encourage HIV/AIDS education and prevention, and their efforts have thus far been somewhat successful. People continue to die from the disease, but the rate of new cases has slowed considerably.

Educational programs continue to use theatre as a major medium for informing the public of health, political, and social concerns, despite the statistical improvements and the continuation of basic prevention information. The National AIDS Coordinating Agency (NACA), the brainchild of the Botswana Training Authority (BOTA), is now a primary sponsor of the BOTA HIV/AIDS Drama Contests that occur every year. BOTA's chief executive officer explained that "the overall goal is to encourage and harness positive behaviour and attitude change among learners and out of school youth through drama competitions". ${ }^{2}$ At this competition, audiences see an array of performances that utilize song, dance, and speech to convey the message of the horrors and concerns surrounding HIV/AIDS. However, other individual AIDS presentations tour Africa throughout the year, through a variety of non government organizations, the United Nations, and universities. With the number of skits broaching this topic every year, it is possible to conclude that performances about health education and HIV/AIDS have become redundant and excessive, while lacking insightful information.

\section{Current Theatre Education}

There is no institution of higher learning with a performing arts program in Botswana. The University of Botswana does not have a specific theatre program, but there is one English class that performs drama. The absence of performance education indicates the low value of theatre among scholars and in the country as a whole. Rather than being valued as an economic or creative industry, theatre is relegated to an alternative form of communication.

An analysis of the class performance history indicates a distinct interest in both political and historical theatre. The website for University of Botswana's English Department included a course synopsis of previous productions as they "seek cooperation with agencies directly involved in social transformation". ${ }^{22}$ The creation of I Love My Country But... was particularly influential. The play dealt with the issues of 
gender rights and mixed marriages. The site reads, "A few months after the play's first performance, the Botswana Parliament amended sections 3,4 \& 5, the gender discriminatory sections of the Citizenship Act". ${ }^{22}$ These are stupendous presentation results. However, it should be noted that even if the ideas are based on good intentions, a heavy agenda can force the educational theatre into the realm of propaganda. The tradition of didactic theatre continues to be encouraged by the present education system.

Educators need to be aware that Botswana has evolved as a country since its independence in 1966 . When Theatre for Development was introduced, Botswana was among the 25 poorest and least developed countries in the world. ${ }^{11}$ However, due to the development of a lucrative diamond industry, Botswana now enjoys an improved financial status and educational opportunities. UNICEF statistics reveal that since 2007 Botswana's literacy rate has risen to $81 \%$. $^{3}$ This is evidence of a communication evolution.

This shift in educational and financial status has overshadowed dependence on theatre for educational purposes. Citizens are now able to receive the same information through many different media sources. As a middle income country, Botswana has access to a greater selection of communication tools, such as the internet, radio, and televisions. Ergo, there is a constant supply of accessible and current educational materials. Theatre still continues to promote community contemplation, but it is no longer the best tool for the job.

Like the colonialists of centuries past, North Americans and Europeans continue the attempt to educate the people of the developing world by teaching "proper" and "more advanced" technology, lifestyles, and foreign artistic techniques, such as theatre. The Theatre for Development programs which were initiated in the 1970s functioned in the same manner as the colonialist theatre half a century earlier. Even with the greatest intentions, these educational programs run the risk of insinuating racial superiority, and can hinder the success of the program they are trying to promote. In essence, this could be considered neo-colonialist activity.

One strategy to avoid patronizing the viewers through racist neo-colonialist actions is to hire indigenous people to lead the programs. Any organization can support a project financially, but they need to staff the programs with people who fully understand the political atmosphere, social stigmas, community hierarchies, and government facilities that help or hinder success. When Theatre for Development was first created, "there was a desire to displace the domesticating 'top-down' approach to communication with a more participatory 'bottom-up' approach". ${ }^{12}$ Theatrical presentations were utilized because they allowed for horizontal communication among peers, rather than instructions by "superiors" from outside the community.

\section{FUTURE OF THEATRE FOR DEVELOPMENT IN BOTSWANA}

Popular theatre for culture and development continues the tradition of lecturing the indigenous peoples about outside technologies and beliefs. Its very nature and purpose reminds audiences that they are behaving incorrectly and must either change or develop. "The reason TfD is always seeking change is to be found in the nature of the environment in which it is practised". ${ }^{1}$ Truthfully, it does not exist in socalled 'first world' countries. It is always initiated in locations where basic human needs are not provided, such as clean drinking water, health care, access roads, and electricity.

Botswana, however, is one of the most successful and developed countries in Africa. BBC News reports that Botswana is stable, democratic, "is relatively free of corruption and has a good human rights record". 7 Since independence in 1966, the welfare of the people has greatly improved. In a country with such a comparatively high standard of living, it seems inappropriate to encourage a theatrical education style that is associated with countries that are considered terribly underdeveloped.

Educational Theatre greatly affected current theatre practises in Botswana. The style of theatre was influenced both by the combination of indigenous, collective, community, and colonial performance traditions. At its worst, Theatre for Development "merely offers predictable instrumentalist messages pre-planned by nongovernmental organization (NGO) development agencies. At its best, it allows communities to create their own plays (usually in conjuncture with facilitators) to comment upon or challenge existing social attitudes, structures, and hierarchies". ${ }^{13}$ The message is the main focus and purpose of the piece, rather than the method of delivery. Since such a lack of effort is often placed upon utilizing local cultural modes, their development and celebration do not occur, thereby suppressing cultural styling. Educational theatre is the continued tradition of colonialism and continues to exert control over the development of theatre in Botswana today.

\section{CONCLUSIONS}

There are significantly few theatre productions in Botswana that occur outside of the realm of Theatre for Development and its educational agenda. Even then, there are not many productions that have been made without financial backing from educational development associations and institutions. The University of Botswana and the government of Botswana have continued to promote the use of theatre for educational purposes. The two main sources that have led to Theatre for Development are the colonial tradition of theatre as propaganda, and the localized tradition of community theatre. This combination has encouraged a theatre style 
founded on spreading information for the improvement of society, rather than exploring culture and individual reflection on society.

Education has been placed as the central mandate for promoting the performance agenda, with artistic exploration being a secondary tool. The reality of the status of this mandate should not be considered either good or bad. It should simply be recognized for what it is and the positive and negative results that it creates. Informative and educational performances have the tendency to be static and akin to the style of lectures. This can deter audiences from attending. On the other hand, the same performances can also be inspiring and influential. However, due to the distinct lack of theatrical presentations available in Botswana, educational theatre has ostracized audiences. Colonial theatre education has remained an integral part of Botswana's theatrical performances to date. It is only through the free development of theatre enforced by indigenous values and local communities that theatre can reflect Botswana culture. The mirror cannot be held up to nature until the artists discover truth and creation within.

\section{REFERENCES}

1. Abah, Oga S. "Creativity, participation and change in Theatre for Development practice." The Performance Arts in Africa. Ed. Frances Harding. London: Routledge, 2002.

2. "Botswana: Naca to Sponsor Bota HIV/AIDS Drama Contests." 17 Aug. 2009. AllAfrica Global Media. 18 Nov. 2009 Retrieved from http://allafrica.com/stories/200908171568. html.

3. "Botswana: Statistics." unicef. 26 Feb. 2004. UNICEF. 29 Nov. 2009 Retrieved from http://www.unicef.org/ infobycountry/botswana_statistics.html.

4. Bourgault, Louise M. Playing for Life: Performance in Africa in the Age of AIDS. Durham: Carolina Academic Press, 2003.

5. Byam, Dale L. Community in Motion: Theatre for Development in Africa. London: Bergin \& Garvey, 1999.

6. Chang, Dong-Shin. THST*2010 Theatre Historical Studies. Guelph, ON: University of Guelph, 24 Sept. 2008.

7. “Country Profile: Botswana.” BBC News. 20 Oct. 2009. BBC. 1 Nov. 2009 Retrieved from http://news.bbc.co. uk/2/hi/africa/country_profiles/1068674.stm.
8. Dodson, Paul. "Maitisong Festival." Festivals \& Events. 2009. 2camels. 29 Nov. 2009 Retrieved from http://www.2camels.com/maitisong-festival.php.

9. "English to Setswana Dictionary." Dicts.info - free dictionaries project. 2009. Dicts.info. 20 Oct. 2009. Retrieved from http://www.dicts.info/dictionary.php?11=English\&12=S etswana.

10. Fortier, Mark. Theory/theatre: an introduction. London: Routledge. 2002.

11. Hanemann, Ulrike. Literacy in Botswana. March 2005. UNESCO Institute for Education. 18 Nov. 2009 http://portal.unesco.org/education/en/files/43531/11315 372211Hanemann_U_Botswana.doc/Hanemann_U_Bot swana.doc.

12. Kerr, David. African Popular Theatre. London: James Curry Ltd., 1995.

13. Kerr, David. "Central and Southern Africa." The Columbia Encyclopedia of Modern Drama. Eds. Gabrielle H. Cody and Evert Sprinchorn. Vol. 1. New York: Columbia University Press, 2007.

14. Kidd, R. From People's Theatre for Revolution to Popular Theatre for Reconstruction: Diary of a Zimbabwean Workshop. Toronto: CESO, 1984.

15. Kidd, Ross, and Martin Byram. Popular Theatre and Non-Formal Education in Botswana: A Critique of Pseudo-Participatory Popular Education. Toronto: The Participatory Research Group, 1982.

16. Masisi. Personal Interview. 6 Aug. 2009.

17. Mda, Zakes. When People Play People: Development Communication Through Theatre. London: Zed Books Ltd., 1993.

18. Mlama, Penina Muhando. Culture and Development. Uppsala: Nordiska Afrikainstitutet, 1991.

19. Odhiambo Christopher J. "Voices from the Margins." Theatre, Performance and New Media in Africa. Eds. Susan Arndt, Eckhard Breitinger, and Marek Spitczok Von Brisinski. Germany: Bayreuth, 2007. 69-77.

20. Okagbue, Osita. African Theatres and Performances. New York: Routledge, 2007.

21. Shakespeare, William. Hamlet. New York: Barron's Educational Series Inc., 2003.

22. "UBE 423: University of Botswana Student Drama." University of Botswana English Department. 23 Jan. 2000. University of Botswana. 15 Sept. 2009. Retrieved from http:/www.thuto.org/ englishold/theatre/ube423.htm.

23. Warren, Lee. The Theatre of Africa. New Jersey: Prentice-Hall Inc., 1975. 